\title{
Reflexiones sobre la filosofía del Dr. Alejandro Serrano a través del segundo tomo de su obra
}

\section{Comentario de Juan Bautista Arríen}

Desde diferentes plataformas, Alejandro ha ido armando un pensamiento sólido, coherente, flexible, creador y sobre todo comprometido con la realidad que desafía al ser humano en sus múltiples acciones y manifestaciones humanas, sociales, históricas, políticas, éticas y culturales. Todo ello, "con la voluntad que anida al ser humano de continuar buscando las respuestas a las interminables preguntas por los seres y el mundo y la fe que no deja desfallecer la esperanza de construir la verdad, aceptando que la filosofía debe buscar la parte de la verdad que se manifiesta en cada tiempo histórico, porque la verdad no es más que el proceso de construir la verdad sólo posible al insertarse y reinventarse el hombre en la historia”.

En coherencia con la filosofía comprometida, Alejandro vive la realización de la filosofía como quehacer humano, como diálogo, como compromiso solidario con el destino del ser humano sobre la tierra, ser humano que carga en la actualidad el drama de su ruptura con él mismo, con los otros, con el medio ambiente y con la trascendencia.

En este sentido, según Alejandro "esta conducta de compromiso y de solidaridad de la razón con el destino del hombre sería la base para construir una nueva ética y nueva axiología”.

¿Cómo encontrar el hilo conductor que atraviesa el pensamiento de Alejandro, tan amplio, denso, diverso y comprometido en el momento estratégico de una etapa particular de la filosofía y de nuestro país? El hilo conductor me parece encontrarlo dando vida a cuatro núcleos de los que se desprenden múltiples ramificaciones que conforman el engranaje extraordinario de una diversidad que en su propia entraña reclama una unidad que sintetice el sentido final de toda la realidad en su evolución global hacia el desarrollo humano a lo largo del tiempo.

Esos cuatros núcleos de pensamiento, según interpretación personal, son: el ser humano, la historia, la libertad y la ética. La filosofía de Alejandro transita, se encarna y se despliega en cada uno de esos núcleos de pensamiento.

El esfuerzo de su filosofía está lanzado a formar un haz que recoge momentos clave del pensamiento filosófico universal, introduciéndose con aliento propio en cada uno de esos núcleos esencialmente dinámicos y creativos. Para ello es necesario analizar el cauce 
por donde transcurre el recorrido del ser humano individual y social, creador y recreador a la vez que usuario de la historia; activando así la libertad para convertirse y hacer avanzar la historia en cuanto sentido de la comunidad humana; libertad e historia que conduzcan al ser humano a comprometerse con el sentido y finalidad de la vida en comunidad donde tiene su espacio propio e insustituible la ética, garantía última de la convivencia humana en sus distintas expresiones de sociedad y de evolución permanente.

Para ello, Alejandro se introduce en cada pensador y sistema no para ser atrapado por ellos sino más bien para cargar las alforjas del quehacer filosófico propio y con ese peso a cuestas avanzar y seguir avanzando porque la filosofía es inagotable, porque es el caminar del hombre hacia su propio misterio, su ser siempre inacabado y por tanto siempre perfectible.

Alejandro penetra en el sustrato del pensamiento filosófico universal, abierto, plural, histórico, permanente, siempre haciéndose y por ello cargando algo de lo anterior o de otros pensadores, y lo conduce a la creación de una síntesis superior de la filosofía elaborada por el pensamiento de todos los filósofos y de todos los tiempos, síntesis que es perfecta unidad pero esencialmente resultado de la enorme diversidad del pensamiento creador.

El choque de ideas, lo mismo que el empuje emanado de cada una de ellas termina en un gran reservorio que a la vez almacena y genera nuevas ideas. Apenas existe componente y factor que van haciendo historia que no lo haya recreado Alejandro. Basta analizar la multitud, pluralidad de reflexiones, concreciones y propuestas transformadoras que llenan los dos primeros tomos de su obra: "Escritos filosóficos y políticos I y II", introduciendo en el tomo II los escritos sobre la Universidad.

En mi doctorado de filosofía (1957), al que dediqué cuatro años, y estudios posteriores sobre la filosofía del hombre (1962), he recorrido la trayectoria de la filosofía, he buceado en sus profundidades, he navegado en sus corrientes y me he detenido a respirar y reflexionar sobre sus pasos y sus contrastes, sobre su necesidad de seguir el camino-espacio abierto por la propia filosofía.

Los estudios de teología y de mi tesis de licenciatura con Karl Rahner sobre Teilhard de Chardin completaron mi visión de un pensamiento necesitado de unidad en el amplio espacio de las ideas y sus repercusiones en la historia del pensamiento universal con cuotas importantes de la filosofía oriental.

Cuando leo la obra filosófica de Alejandro la siento muy mía, me asombra su profundo conocimiento de la filosofía, me asombra su quehacer filosófico y la recreación casi inagotable del mismo con pasado, presente y abierto al futuro en su espacio histórico respirando vida y haciéndose vida en la política, el estado de derecho, los derechos humanos, la ética, la sociedad, la democracia, el mundo, la ciencia, la tecnología, el arte, la globalización, el mercado, la justicia, el socialismo, la enajenación, la civilización, la crisis, etc. Y en el tomo II de manera particular la universidad, todos ellos resortes que activan su reflexión filosófica, una reflexión encarnada y comprometida con la historia y realidad de nuestro país, es decir, una reflexión filosófica también desde Nicaragua. 
Lo admirable de Alejandro es que de todo hace filosofía y a todo lo atraviesa con la filosofía para ayudar a construir y dar sentido, direccionalidad y horizonte a la realidad humana y a todo lo que circunda al ser humano como recreador de esa realidad socializada. Porque el acto creador, Dios lo depositó en el ser humano en el momento extraordinario de la evolución cuando éste devino inteligente y libre. Como dice Alejandro, "el propio pensamiento es parte de la realidad de su historia y evolución" (citar). Para Alejandro, mientras haya un ser humano habrá filosofía porque en él y por él acontece el cambio y se construye la humanidad que no es otra cosa que el hombre ampliado en su historia. Es decir, el ser humano en sus múltiples y extraordinarios capítulos donde se esconde, se expresa y verifica desde lo más sublime hasta lo más degradante del ser humano universal.

Hay algo muy particular en el quehacer filosófico de Alejandro y es que casi siempre está referido a enfrentarse a aspectos y elementos de la realidad conformada por el quehacer humano social en circunstancias determinadas. Por eso su filosofía es una filosofía comprometida con el mundo del ser social orientada hacia la praxis transformadora de ese mundo humano, social, político y cultural.

Su filosofía hace de sus raíces nacionales, emocionales, e incluso de su intuición, el sustento de una reflexión penetrante de la realidad en el más allá de su expresión empírica porque ésta siempre tiene un trasfondo o embrión que oculta su sentido original y esencialmente dinámico o lo que es lo mismo, histórico.

No se trata pues de una simple reflexión, se trata de la reflexión de un pensamiento alimentado por la influencia de casi todas las corrientes filosóficas que han atravesado el devenir filosófico mundial. La reflexión filosófica de Alejandro es más que una reflexión, es una metareflexión o sea una reflexión de la reflexión sobre diferentes reflexiones anteriores interiorizadas en una síntesis superior. Toda reflexión de todo ser humano busca el sentido y posibilidad de cada factor que le afecta en su vida en pos de algo que se presenta como verdad y como base de su compromiso personal. Pero la reflexión del filósofo es cualitativamente superior porque está basada en una reflexión construida sobre reflexiones de otros muchos filósofos sobre los mismos temas. No es lo mismo un análisis que una reflexión filosófica, el análisis posee un espacio limitado y puntual, la reflexión filosófica se adentra más en el conjunto de factores que conforman la realidad.

Por eso la reflexión filosófica de Alejandro, centrada en factores, elementos y hechos sobre el ser humano en su despliegue histórico, posee además de una extraordinaria penetración, el potencial de descubrir, de desocultar, como él dice, el sentido y direccionalidad de todo acontecimiento que deriva del quehacer humano y concluye en el ser humano social responsable y siempre perfectible. De ahí que su filosofía sea también una filosofía sobre la acción y la práctica social, una reflexión sobre hechos y circunstancias de nuestra praxis como país. Su filosofía tiene el carácter de un sólido referente sobre nuestra realidad como país. Esto es muy importante porque su pensamiento se va convirtiendo en un pensamiento colectivo que va anclándose en el ámbito nacional e internacional, de manera especial en la perspectiva de la globalización. Todo país necesita ser sujeto y objeto de su propia reflexión con perspectiva de futuro. Un país carente de reflexión seria, sistemática y prospectiva, en búsqueda razonable de lo que acontece y cómo acontece en él, no tiene fuerza ni perspectiva 
propias de futuro. Es necesario ir más allá de los análisis y encuestas puntuales. Aquí se sitúa el pensamiento filosófico de Alejandro.

Porque no se trata sólo de la globalización como espacio de poder económico y cultural a golpes del mercado, de la comunicación y de la sociedad de consumo, se trata de la verdadera globalización del propio ser humano, dado que todo se hace presente como dimensión auténtica de cada uno de nosotros. El ser humano se ha universalizado.

El hombre, más allá de sí mismo sin dejar de ser él mismo, como individualidad y totalidad única e irrepetible vive en esa universalidad que reclama la presencia de la filosofía y ésta penetra en todo porque su verdad está en llegar al sentido, direccionalidad y trascendencia de todo lo que acontece. El sentido en toda su amplitud dinámica es la razón de ser de todo el universo, de todo ser humano, de los valores, de la vida ciudadana, el cambio climático, las relaciones internacionales, la política, la ciencia, la tecnología, la mujer, la juventud, la educación, la universidad, temas que llenan las páginas de este segundo Tomo. De ahí que el principio de unidad en la diversidad tenga un sólido fundamento legitimado por la historia del pensamiento y por el propio desarrollo sostenido que se hace Humanidad.

Con esto queremos decir que la filosofía está en las entrañas de todo porque está en la esencia y realidad del ser humano, del que se va generando y desarrollando todo en tanto que la evolución de la Humanidad es un juego extraordinariamente conjugado de la inteligencia, el conocimiento, la voluntad, la libertad, la intuición, la emoción, los sentimiento, las hazañas y también las grandes torpezas y maldades del ser humano. La filosofía desde Sócrates camina a la par del ser humano y sus decisiones, a través de la historia encarnada. Lanzada a buscar y construir la verdad, la filosofía indaga y se preocupa por lo que falta o lo que enriquece la realidad global del ser humano.

La filosofía se desgasta y se fortalece en el devenir del ser humano, artífice del mundo humano social, económico y cultural. Este devenir necesita de un pensamiento, de una reflexión, de una praxis permanente a fin de sustentar y alimentar el sentido, la convivencia y el desarrollo humano en un mundo con amplio peso de lo material y de potencial espiritual.

La filosofía es siempre parte inherente del ser y quehacer humanos anclados en la realidad para ayudar a mejorarla, transformarla y trascenderla en beneficio y bienestar de toda la humanidad. En palabras de Alejandro "la filosofía es la posibilidad siempre abierta de hacer realidad la razón y racional la realidad”. He aquí la razón de ser del filosofo, en esto consiste la búsqueda incansable de la verdad sin dicotomías, en la construcción incansable de la verdad que para mí es en último término la convivencia armoniosa entre los seres humanos y el bienestar de cada ciudadano del mundo, ahí desemboca la verdad de cada ciudadano del mundo.

Alejandro es un caminante con la filosofía, haciendo camino al andar, avanzando por avenidas, trochas y atajos para ir encontrando y alcanzando el sentido del hombre y de su obra global en este mundo siempre haciéndose, siempre perfectible, de aciertos, contrastes y contradicciones pero con posibilidad de presente y futuro, por eso la filosofía se mueve en la orbita de generación positiva. Todo lo que acontece es adorable decía Teilhard de Chardin, 
todo apunta a la esperanza. La filosofía busca llegar al sentido último de todo con el nombre de realidad para orientar su transformación y esto es esperanza. Más allá de las aparentes desesperanzas, el hecho de que todos los filósofos busquen la verdad, el sentido de todo es un signo de esperanza. Creo en la esperanza porque en el fondo todos nos reunimos en la esperanza. Soy optimista respecto al futuro convencido de que solo es posible el camino de la historia hacia algo siempre mejor.

En su II tomo, Alejandro manifiesta su talante y su ethos universitario, constatando y alimentando el hecho de que la universidad es en sí el núcleo y la plataforma activos de la alta inteligencia y del sólido aliento ético cuyo sustento esencial es la filosofía en tanto la Universidad está hecha y comprometida para crear conocimiento, ciencia, innovación, conciencia crítica y valores éticos. La universidad aparece en el pensamiento de Alejandro como el punto de encuentro de las ideas y de las realidades, el laboratorio intelectual y ético, la puerta de salida del desarrollo y la cultura universal, la plataforma del humanismo beligerante del recordado Rector Mariano Fiallos Gil. A la libertad por la universidad lema de la UNAN que junto con la libertad os hará libres de la UCA dan a la libertad un sentido de acción comprometida uniendo libertad y verdad, anclas de su auténtica autonomía.

No es coincidencia que los filósofos que han constituido los momentos claves del pensamiento y de la ciencia, incluso con sus propios sistemas, hayan sido y siguen siendo la gran mayoría profesores universitarios. Los filósofos griegos en sus cátedras muy personales, Descartes, Kant, Hegel, Husserl, Bergson, Dilthey, Nietzsche, Heidegger, Jaspers, Ortega y Gasset, Zubiri, Zea, Althusser, Popper, Derrida, Lyotard. A una universidad que no esté anclada y agitada en el aliento de la filosofía, le falta espíritu innovador y transformador que abarque toda la dimensión del ser humano, carece de universalidad porque le falta algo esencial a ella.

Hoy en día esto parece una excepción pues la técnica, la ciencia, la práctica y el desarrollo están mediatizados por la tecnología y el pensamiento científico aplicable, los que por su valor positivista, pragmático, práctico y económico sobrepasan con creces al pensamiento del espíritu y a la dimensión humana en toda su plenitud. En su obra, Alejandro, Rector y Profesor, realiza una extraordinaria disección entrañable y positiva, humanista, científica y política de la universidad. Su penetración en la esencia, historia y funciones de la Universidad comprometida constituye uno de los mejores tratados que yo conozca, coincidente con la extraordinaria y casi insuperable obra del Dr. Carlos Tünnermann.

A la Universidad se le ha abierto la enorme oportunidad y responsabilidad, la de humanizar el conocimiento y la ciencia, lo que es lo mismo que ponerlos al servicio del desarrollo humano y de la convivencia de la familia humana. La esencia de la ciencia no es crear riqueza material es crear bienestar humano. La ciencia pertenece al ser humano y no éste a la ciencia y también pertenece a la universidad. En esta encrucijada histórica y desde ella universitaria me atrevo a afirmar la indisoluble relación que se debe dar entre la ética y el desarrollo. Sin ética, sin aceptar y sin hacer del ser humano el centro del sistema heliocéntrico del mundo actual, no habrá desarrollo verdadero en cuyos beneficios todos los seres humanos seamos partícipes. La ética es a la postre el alma encarnada de la filosofía y el fundamento del desarrollo. Ética y Desarrollo son inseparables. 
Me refiero, coincidiendo con Alejandro, a la ética transformadora. Es decir, a la posición normativa frente a la vida, la historia y la sociedad, que empuja a los individuos y las organizaciones políticas a luchar para cambiar la realidad existente teniendo como finalidad el bienestar global de toda la gente, lo que significa subvertir la moralidad social dominante en muchos de nuestros países. El título, "Escritos filosóficos y políticos I y II", nos indica claramente la relación de la filosofía con la vida de la polis o de la comunidad organizada por tanto con la política.

Recientemente Copenhague nos ha demostrado que el inmenso problema del cambio climático sólo es posible de resolver partiendo de los principios éticos compartidos y profundamente sentidos. El cambio climático no es sólo una necesidad científica sino un imperativo ético. La humanidad ha llegado a un momento crítico en el que los pueblos y las naciones tendrán que reconocer su solidaridad mutua y con la tierra. Este imperativo ético es impostergable.

En este sentido, la modernidad con el poder de la razón quedó incrustada en la postmodernidad y ésta se debate en ideas que chocan entre sí perdiendo en ocasiones el punto Omega de que habla Teilhard de Chardin, adoleciendo de equilibrio sostenido debido al cruce de ideas excelentes en búsqueda de aproximaciones humanas pero sin llegar a consensos básicos en los que se consolida el desarrollo común de la colectividad humana. La postmodernidad, pese al extraordinario despliegue de la racionalidad mediante el desarrollo del pensamiento científico y de la multiplicidad de ideas que buscan soluciones universales, parece no poseer la fuerza suficiente como para salir de sus incertidumbres y enfrentar el problema planetario del cambio climático que avanza con su amenaza destructora. En ocasiones la postmodernidad aparece más como un conjunto de diferencias, de diversidades que de unidad. Se va imponiendo la diversidad cuando su sentido último está en aportar cuotas claves para la unidad. Así se comprende desde esta nueva perspectiva el sabio principio y central del pensamiento de Alejandro unidad en la diversidad. Según su sentido auténtico, la diversidad busca su sentido último en la unidad y la unidad acoge la aspiración profunda de la diversidad. La unidad del ser humano social se completa en las diferencias.

Los análisis extraordinarios de Alejandro sobre la modernidad, la postmodernidad, la transmodernidad al concluir y fundamentar su principio unidad en la diversidad sitúa a éste como algo realmente original e histórico en este vaivén de la historia humana en la que todo lo humano nos es propio y animado en nuestro medio por la audacia filosófica de Alejandro.

Lo anterior me sugiere, queriendo interpretar el principio filosófico de Alejandro, que ha llegado el tiempo de la ética universal como sustento de la unidad en la diversidad. Quizás sea la ética universal la que llama a la gran y real unidad de la filosofía de la Humanidad en la que se encuentran todas las diversidades. Éste parece ser el derrotero construido por la filosofía en persecución de la verdad y el sentido de la propia Humanidad. Necesitamos la verdad de la Humanidad, de todo lo que es humano y relacionado con lo humano aunque ésta la veamos hecha jirones y pedazos tirados en permanentes choques, violencia, pobreza, exclusiones y enormes diferencias y hasta guerras. Mientras la diversidad bien intencionada que ha caracterizado a la vida de la filosofía con caminos distintos para avanzar hacia la 
verdad continúe avanzando, el principio de la unidad en la diversidad encuentra en la ética universal, reclamada por la humanidad, la verdad humana trascendental. Como dije más arriba, la Humanidad ha llegado a un momento crítico de la historia de la tierra en el que los pueblos y las naciones tienen que reconocer su solidaridad mutua y con la tierra. Siento en esta afirmación la presencia y el reclamo de la unidad en la diversidad, el clima es ahora un cliente importante, insustituible del pensamiento filosófico y del quehacer científico, y el punto de unión de la diversidad. Estamos en la necesidad de la unidad de la ciencia y de la ética.

Como filósofo visualizo que en el planeta tierra y en el mundo humano se están dando pasos indetenibles hacia la necesidad de una unidad coincidente con el reclamo de la filosofía de Alejandro. La filosofía tiene ahora el nombre de Humanidad. Presiento y estoy convencido de que el pensamiento de Alejandro, según me habla su extraordinaria obra filosófica, camina hacia la verdad de una Humanidad en la que se den las condiciones para que todos seamos humanos partícipes de la misma Humanidad y de todo su potencial. Unidad en la diversidad.

Esta es la utopía de la filosofía, la que impulsa su caminar. Ella va haciéndose mientras el ser humano y su mundo sean perfectibles, mientras la verdad vaya encontrándose en la vida y sentido de la Humanidad, en todo lo humano y su circunstancia.

El sentido que construye la filosofía es el sentido de la Humanidad, buscar y construir en todo ese sentido es en último término la verdad que construye la filosofía mediante su caminar incesante en busca de la verdad.

Uno de esos caminantes infatigables es Alejandro. Todo esto que los filósofos construimos con nuestro pensamiento y compromiso ético para el bien de toda la gente es demasiado importante para dejarlo sólo en manos de los políticos. Construyamos la verdad compartida de la Humanidad, la verdad del ser humano universal, entre todos y con todos, haciendo realidad el principio unidad en la diversidad. Es reto del filósofo ver más allá de lo visible y hacer más allá de lo posible. 